\title{
Ancient coexistence of norepinephrine, tyramine, and octopamine signaling in bilaterians
}

\author{
Philipp Bauknecht and Gáspár Jékely*
}

\begin{abstract}
Background: Norepinephrine/noradrenaline is a neurotransmitter implicated in arousal and other aspects of vertebrate behavior and physiology. In invertebrates, adrenergic signaling is considered absent and analogous functions are performed by the biogenic amines octopamine and its precursor tyramine. These chemically similar transmitters signal by related families of G-protein-coupled receptors in vertebrates and invertebrates, suggesting that octopamine/tyramine are the invertebrate equivalents of vertebrate norepinephrine. However, the evolutionary relationships and origin of these transmitter systems remain unclear.

Results: Using phylogenetic analysis and receptor pharmacology, here we have established that norepinephrine, octopamine, and tyramine receptors coexist in some marine invertebrates. In the protostomes Platynereis dumerilii (an annelid) and Priapulus caudatus (a priapulid), we have identified and pharmacologically characterized adrenergic $a 1$ and $a 2$ receptors that coexist with octopamine $a$, octopamine $\beta$, tyramine type 1 , and tyramine type 2 receptors. These receptors represent the first examples of adrenergic receptors in protostomes. In the deuterostome Saccoglossus kowalevskii (a hemichordate), we have identified and characterized octopamine a, octopamine $\beta$, tyramine type 1, and tyramine type 2 receptors, representing the first examples of these receptors in deuterostomes. $S$.

kowalevskii also has adrenergic a1 and a2 receptors, indicating that all three signaling systems coexist in this animal. In phylogenetic analysis, we have also identified adrenergic and tyramine receptor orthologs in xenacoelomorphs.

Conclusions: Our results clarify the history of monoamine signaling in bilaterians. Given that all six receptor families (two each for octopamine, tyramine, and norepinephrine) can be found in representatives of the two major clades of Bilateria, the protostomes and the deuterostomes, all six receptors must have coexisted in the last common ancestor of the protostomes and deuterostomes. Adrenergic receptors were lost from most insects and nematodes, and tyramine and octopamine receptors were lost from most deuterostomes. This complex scenario of differential losses cautions that octopamine signaling in protostomes is not a good model for adrenergic signaling in deuterostomes, and that studies of marine animals where all three transmitter systems coexist will be needed for a better understanding of the origin and ancestral functions of these transmitters.
\end{abstract}

Keywords: Octopamine, Tyramine, Norepinephrine, Noradrenaline, GPCR evolution, Neurotransmitter, Saccoglossus, Platynereis, Priapulus, Xenacoelomorpha

\footnotetext{
* Correspondence: gaspar.jekely@tuebingen.mpg.de

Max Planck Institute for Developmental Biology, Spemannstrasse 35, 72076

Tübingen, Germany
}

(c) The Author(s). 2017 Open Access This article is distributed under the terms of the Creative Commons Attribution 4.0 International License (http://creativecommons.org/licenses/by/4.0/), which permits unrestricted use, distribution, and reproduction in any medium, provided you give appropriate credit to the original author(s) and the source, provide a link to the Creative Commons license, and indicate if changes were made. The Creative Commons Public Domain Dedication waiver (http://creativecommons.org/publicdomain/zero/1.0/) applies to the data made available in this article, unless otherwise stated. 


\section{Background}

Norepinephrine is a major neurotransmitter in vertebrates with a variety of functions, including roles in promoting wakefulness and arousal [1], regulating aggression [2], and autonomic functions such a heart beat [3]. Signaling by the monoamine octopamine in protostome invertebrates is often considered equivalent to vertebrate adrenergic signaling [4], with analogous roles in promoting aggression and wakefulness in flies [5, 6], and the regulation of heart rate in annelids and arthropods [7, 8]. Octopamine is synthesized from tyramine (Fig. 1a) which itself also acts as a neurotransmitter or neuromodulator in arthropods and nematodes [4, 9-15]. Octopamine and norepinephrine are chemically similar, are synthesized by homologous enzymes [16, 17], and signal by similar but not orthologous G-protein-coupled receptors (GPCRs) [4, 18].

Tyramine also signals via non-orthologous receptors in invertebrates and vertebrates. In insects and nematodes, tyramine signals via a GPCR that is related to octopamine receptors $[12,19]$. In vertebrates, tyramine is only present at low levels and signals via the trace-amine receptors, a vertebrate-specific GPCR family only distantly related to the invertebrate tyramine receptors $[20,21]$. Given these differences, the precise evolutionary relationships of these monoamine signaling systems are unclear.

The evolution of neurotransmitter systems has been analyzed by studying the distribution of monoamines or biosynthetic enzymes in different organisms [22]. This approach has limitations, however, because some of the biosynthetic enzymes are not specific to one substrate [16] and because trace amounts of several monoamines are found across many organisms, even if specific receptors are often absent [22]. For example, even if invertebrates can synthesize trace amounts of norepinephrine, these are not considered to be active neuronal signaling molecules, because the respective receptors are lacking. Consequently, the presence of specific monoamine receptors is the best indicator that a particular monoamine is used in neuronal signaling $[11,23]$.

To clarify the evolutionary history of adrenergic, octopamine, and tyramine signaling in animals, we undertook a comparative phylogenetic and pharmacological study of these receptor families in bilaterians. Bilaterian$\mathrm{s}$-animals with bilateral symmetry-comprise protostomes, deuterostomes, and xenacoelomorphs [24]. Deuterostomes include chordates and ambulacrarians (hemichordates and echinoderms), and protostomes are formed by the clades Ecdysozoa, Lophotrochozoa (Spiralia), and Chaetognatha. Ecdysozoa includes arthropods, nematodes, priapulids and other phyla. Lophotrochozoa includes annelids, mollusks, and other, mostly marine groups. Xenacoelomorpha, a group including acoel flatworms, nemertodermatids, and Xenoturbella, has been proposed to belong to the deuterostomes, or represent a sister group to all remaining bilaterians [25-27]. Here, we have attempted to establish the orthologous relationships of adrenergic, octopamine, and tyramine receptors across bilaterians. We found that six receptor families originated at the base of the bilaterian tree. We then pharmacologically characterized adrenergic receptors from an annelid and a priapulid, and octopamine and tyramine receptors from an annelid and a hemichordate. The broad phylogenetic sampling and comparative pharmacology paint a richer picture of the evolution of these receptors, characterized by ancestral coexistence and multiple independent losses.

\section{Results}

Using database searches, sequence-similarity-based clustering, and phylogenetic analysis, we reconstructed the phylogeny of $\alpha 1, \alpha 2$, and $\beta$ adrenergic, octopamine $\alpha$, octopamine $\beta$, and tyramine type- 1 and type- 2 receptors. Each family formed well-resolved clusters in a sequencesimilarity-based clustering analysis and well-supported clades in molecular phylogenetic analysis (Fig. 1b, c and Additional file 1).

We identified several invertebrate GPCR sequences that were similar to vertebrate adrenergic $\alpha 1$ and $\alpha 2$ receptors (Fig. 1b, c). An adrenergic $\alpha 1$ receptor ortholog is present in the sea urchin Strongylocentrotus purpuratus. Adrenergic $\alpha 1$ and $\alpha 2$ receptors were both present in Saccoglossus kowalevskii, a hemichordate deuterostome (Fig. 1b, c and Additional files 1, 2, and 3), as previously reported [28]. We also identified adrenergic $\alpha 1$ and $\alpha 2$ receptor orthologs in annelids and mollusks (members of the Lophotrochozoa), including Aplysia californica, and in the priapulid worm Priapulus caudatus (member of the Ecdysozoa) (Fig. 1b, c and Additional files 1, 2, and 3). Adrenergic $\alpha$ receptors are also present in a few arthropods, including the crustacean Daphnia pulex and the moth Chilo suppressalis (the Chilo $\alpha 2$ receptor was first described as an octopamine receptor [29]), but are absent from most other insects (Additional files 1, 2, and 3). Adrenergic $\alpha 2$ receptors are also present in the xenacoelomorphs Xenoturbella bocki and Meara stichopi. M. stichopi also has two adrenergic $\alpha 1$ receptor orthologs (Fig. 1c and Additional files 1, 2, and 3).

The identification of adrenergic $\alpha 1$ and of $\alpha 2$ receptor orthologs in ambulacrarians, lophotrochozoans, ecdysozoans, and xenacoelomorphs indicates that both families were present in the bilaterian last common ancestor.

Adrenergic $\beta$ receptors are found in chordates, including urochordates and cephalochordates. In addition, we identified an adrenergic $\beta$ receptor ortholog in the 

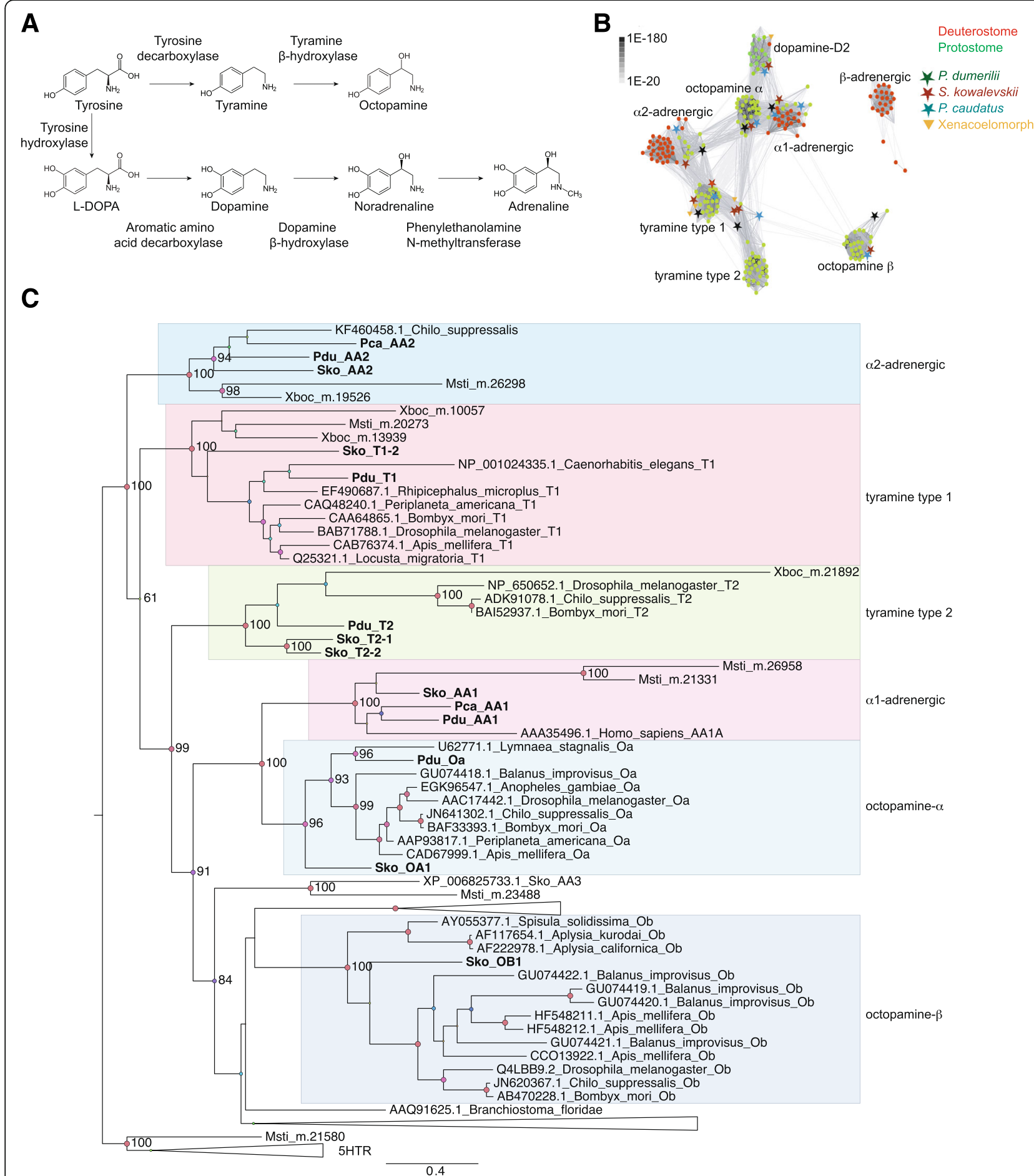

Fig. 1 Biosynthesis of monoamines and phylogeny of adrenergic, tyramine, and octopamine G-protein-coupled receptor (GPCR) sequences. a Biosynthesis of tyramine, octopamine, norepinephrine, and epinephrine from tyrosine. The enzymes catalyzing the reaction steps are indicated. b Sequence-similarity-based cluster map of bilaterian octopamine, tyramine, and adrenergic GPCRs. Nodes correspond to individual GPCRs and are colored based on taxonomy. Edges correspond to BLAST connections of $P$ value $>1$ e-70. c Simplified phylogenetic tree of bilaterian adrenergic, tyramine, and octopamine GPCR sequences. The tree is rooted on $5 \mathrm{HT}$ receptors (5HTR). Abbreviations: Pdu P. dumerilii, Pca P. caudatus, Sko S. kowalevskii, Msti M. stichopi, Xboc X. bocki 
xenacoelomorph M. stichopi (Additional file 4). If xenacoelomorphs are sister to all remaining bilaterians, then this receptor family also originated at the base of Bilateria and was lost from all protostomes.

To characterize the ligand specificities of these putative invertebrate adrenergic receptors, we cloned them from S. kowalevskii, Priapulus caudatus, and the marine annelid Platynereis dumerilii. We performed in vitro GPCR activation experiments using a $\mathrm{Ca}^{2+}$-mobilization assay [30, 31]. We found that norepinephrine and epinephrine activated both the adrenergic $\alpha 1$ and $\alpha 2$ receptors from all three species with half maximal effective concentration $\left(\mathrm{EC}_{50}\right)$ values in the high nanomolar range or lower. In contrast, tyramine, octopamine, and dopamine were either inactive or only activated the receptors at concentrations approximately two orders of magnitude higher (Fig. 2, Table 1). These phylogenetic and pharmacological results collectively establish these invertebrate receptors as bona fide adrenergic $\alpha$ receptors.

To investigate if adrenergic signaling coexists with octopamine and tyramine signaling in protostomes, we searched for octopamine and tyramine receptors in Platynereis dumerilii and Priapulus caudatus. In phylogenetic and clustering analyses, we identified orthologs for tyramine type 1 and type 2 and octopamine $\alpha$ and $\beta$ receptors in both species (Fig. 1b, c and Additional files 5, 6,7 , and 8). We performed activation assays with the Platynereis dumerilii receptors. The tyramine type 1 and type 2 receptors orthologs were preferentially activated by tyramine with $\mathrm{EC}_{50}$ values in the nanomolar range (Fig. 3, Table 1). The Platynereis dumerilii octopamine $\alpha$ receptor was activated by octopamine at a lower concentration than by tyramine and dopamine (Fig. 4, Table 1). The Platynereis dumerilii octopamine $\beta$ receptor was

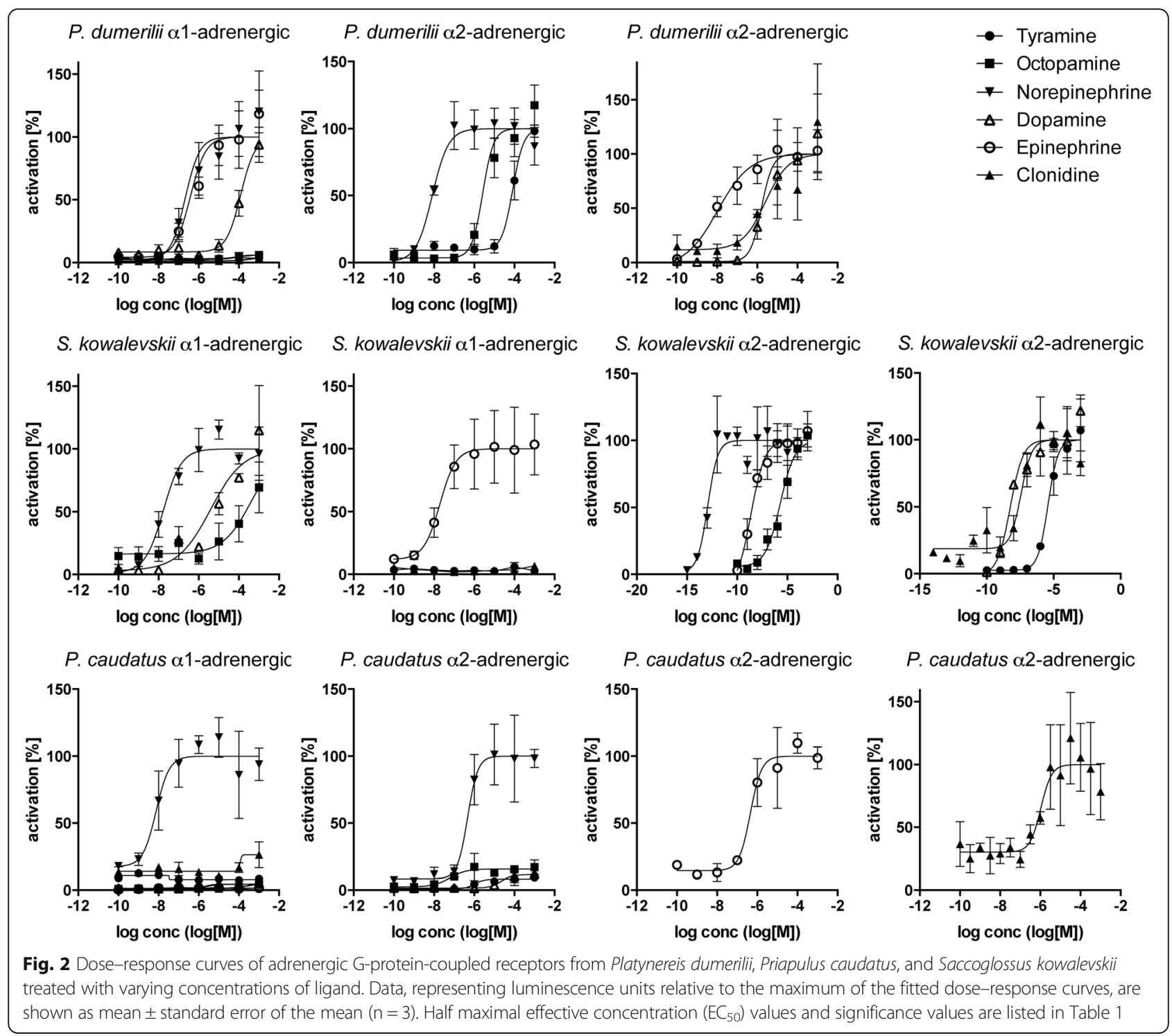




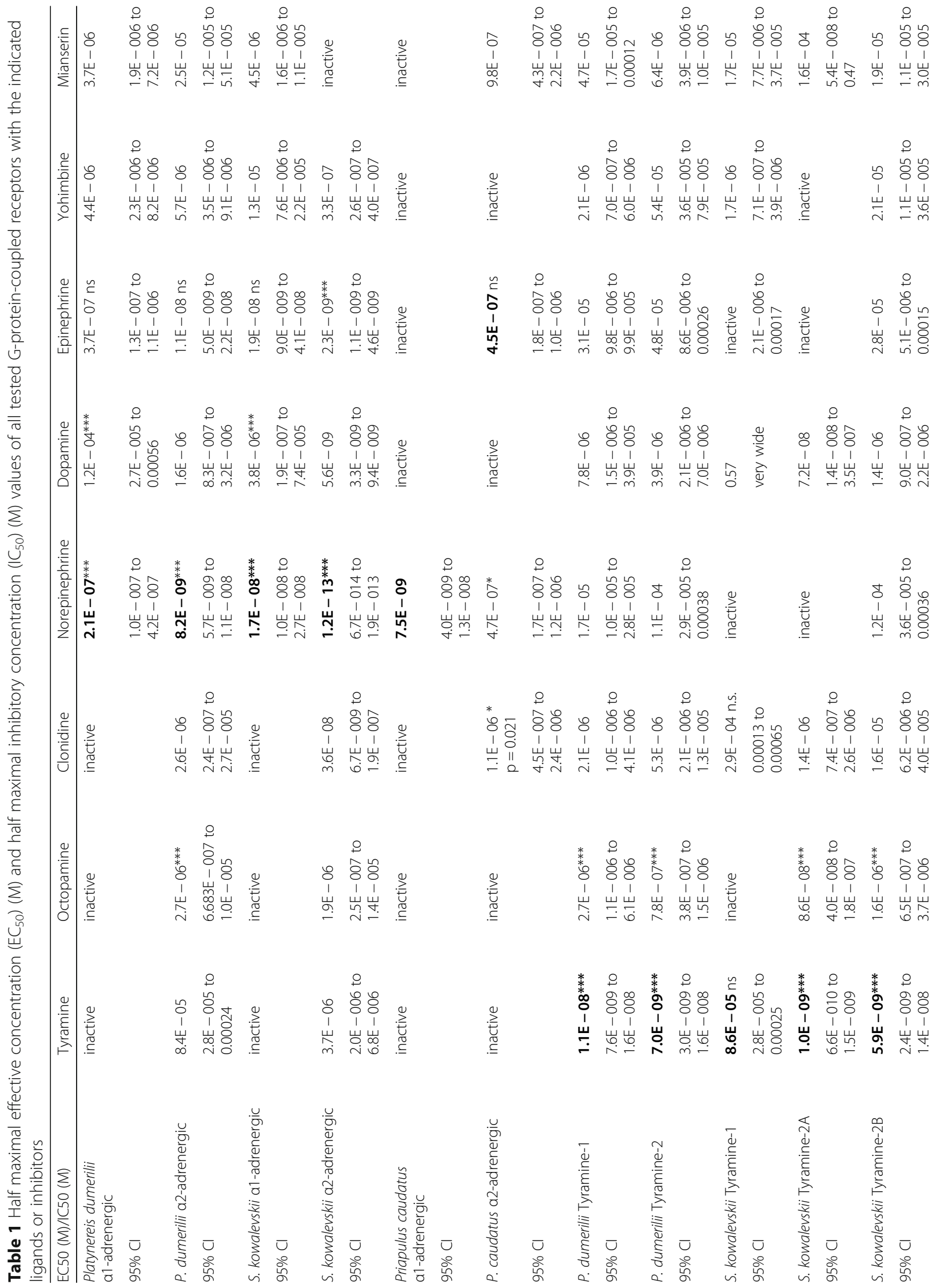




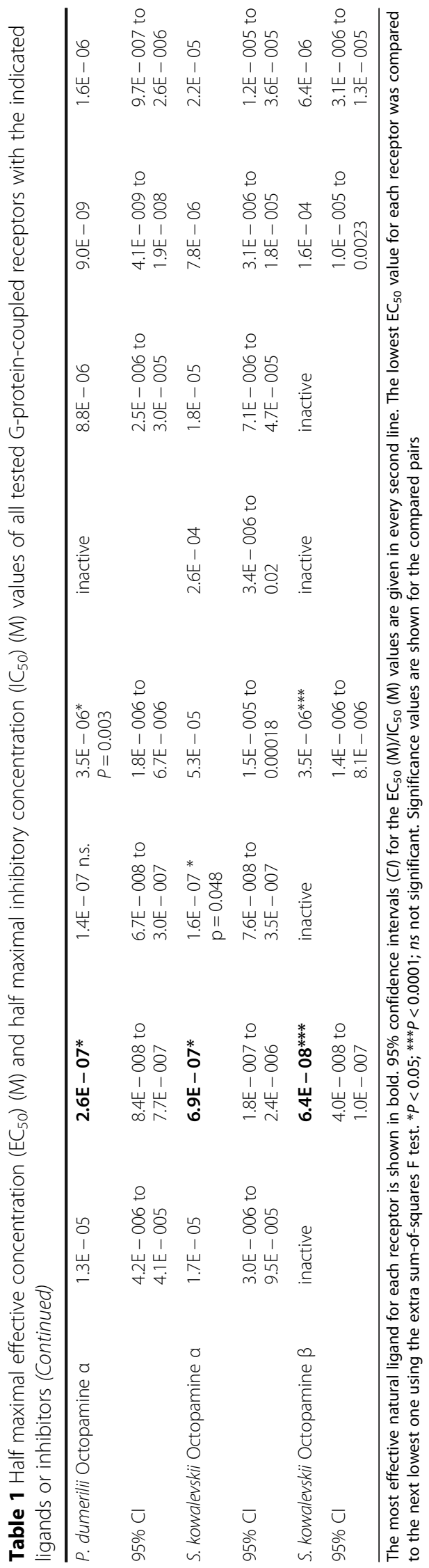




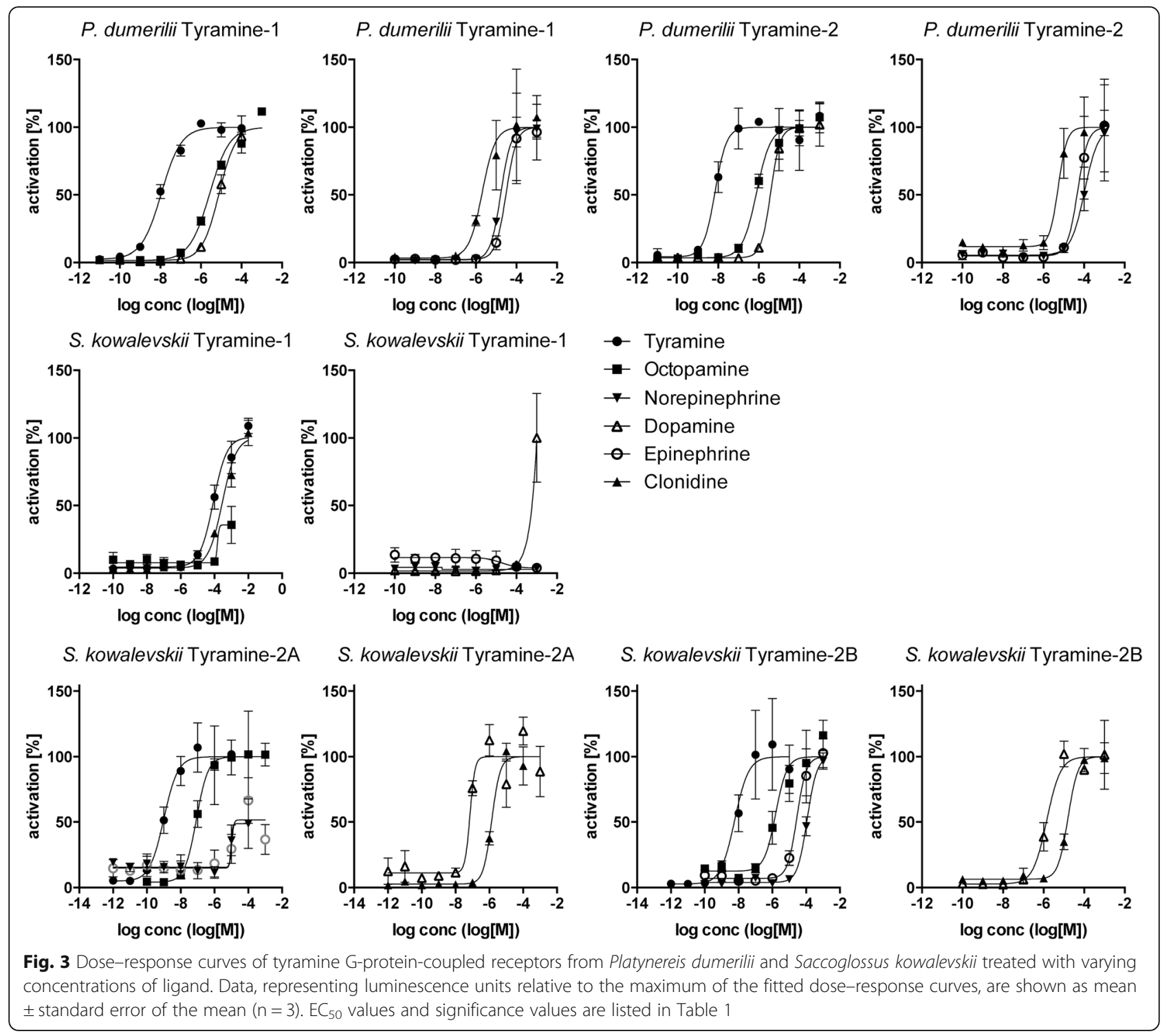

not active in our assay. These results show that specific receptor systems for norepinephrine, octopamine, and tyramine coexist in Platynereis dumerilii and very likely also Priapulus caudatus.

When did tyramine and octopamine signaling originate? To answer this, we surveyed available genome sequences for tyramine and octopamine receptors. As expected, we identified several receptors across the protostomes, including ecdysozoans and lophotrochozoans (Additional files 5, 6, 7, and 8). We also identified receptors for tyramine, but not octopamine, in xenacoelomorphs. However, chordate genomes lacked orthologs of these receptors. Strikingly, we identified tyramine type 1 and 2 and octopamine $\alpha$ and $\beta$ receptor orthologs in the genome of the hemichordate S. kowalevskii (Fig. 1b, c, Additional files 5, 6, 7, and 8). In phylogenetic analyses, we recovered at least one $S$. kowalevskii sequence in each of the four receptor clades (one octopamine $\alpha$, one octopamine $\beta$, two tyramine type 1 , and two tyramine type 2 receptors), establishing these sequences as deuterostome orthologs of these predominantly protostome GPCR families (Additional files 5, 6, 7, and 8).

We cloned the candidate $S$. kowalevskii tyramine and octopamine receptors and performed ligand activation experiments. The $S$. kowalevskii type 2 receptors were preferentially activated by tyramine in the nanomolar range. The type 1 receptor was only activated at higher ligand concentrations. The octopamine $\alpha$ and $\beta$ receptors were preferentially activated by octopamine in the nanomolar range (Figs 3 and 4, Table 1). These data show that octopamine and tyramine signaling also coexist with adrenergic signaling in this deuterostome, as in Platynereis dumerilii and Priapulus caudatus. The presence of tyramine signaling in $S$. kowalevskii is also 

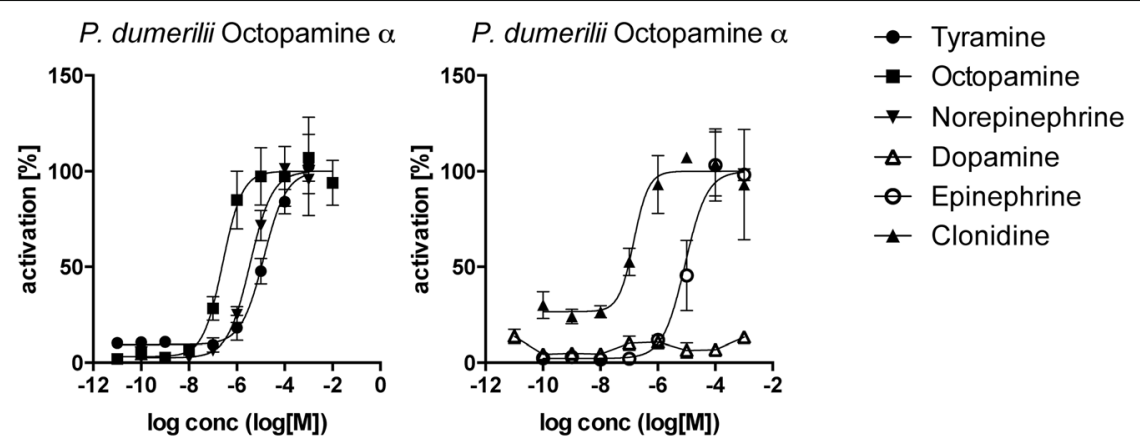

S. kowalevskii Octopamine $\alpha$

S. kowalevskii Octopamine $\alpha$

S. kowalevskii Octopamine $\beta$
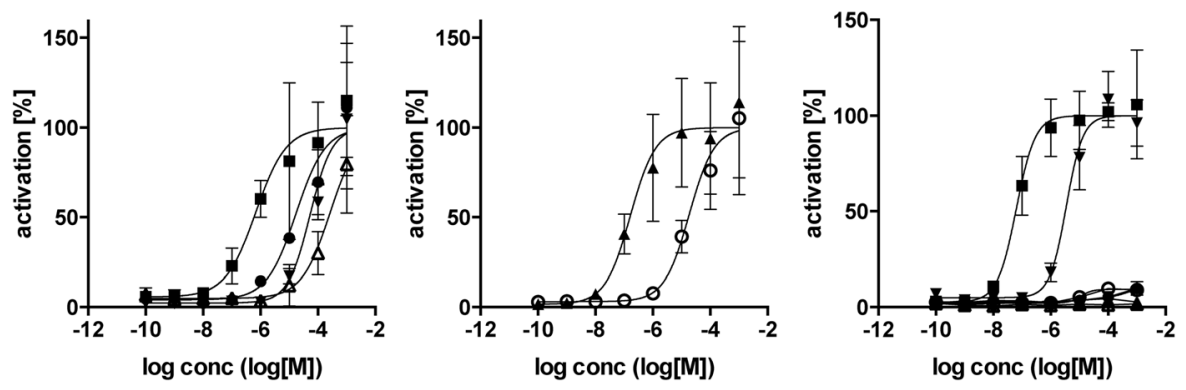

Fig. 4 Dose-response curves of octopamine G-protein-coupled receptors from Platynereis dumerilii and Saccoglossus kowalevskii treated with varying concentrations of ligand. Data, representing luminescence units relative to the maximum of the fitted dose-response curves, are shown as mean \pm standard error of the mean $(n=3)$. Half maximal effective concentration $\left(E C_{50}\right)$ values and significance values are listed in Table 1

supported by the phylogenetic distribution of tyrosine decarboxylase, a specific enzyme for tyramine synthesis [32]. Tyrosine decarboxylase is present in protostomes and S. kowalevskii but is absent from other deuterostomes (Additional file 9). In mammals, aromatic amino acid decarboxylases are involved in synthesizing low amounts of tyramine [33].

We also tested the $\alpha$ adrenergic agonist clonidine and the GPCR antagonists mianserin and yohimbine on several receptors from all three species. These chemicals did not show specificity for any of the receptor types, suggesting these chemicals may not be useful for studying individual biogenic amine receptors in vivo (Table 1 and Additional file 10).

\section{Discussion}

The discovery of adrenergic signaling in some protostomes and xenacoelomorphs and octopamine and tyramine signaling in a deuterostome changes our view on the evolution of monoamine signaling in bilaterians (Fig. 5). It is clear from the phylogenetic distribution of orthologous receptor systems that at least six families of octopamine,

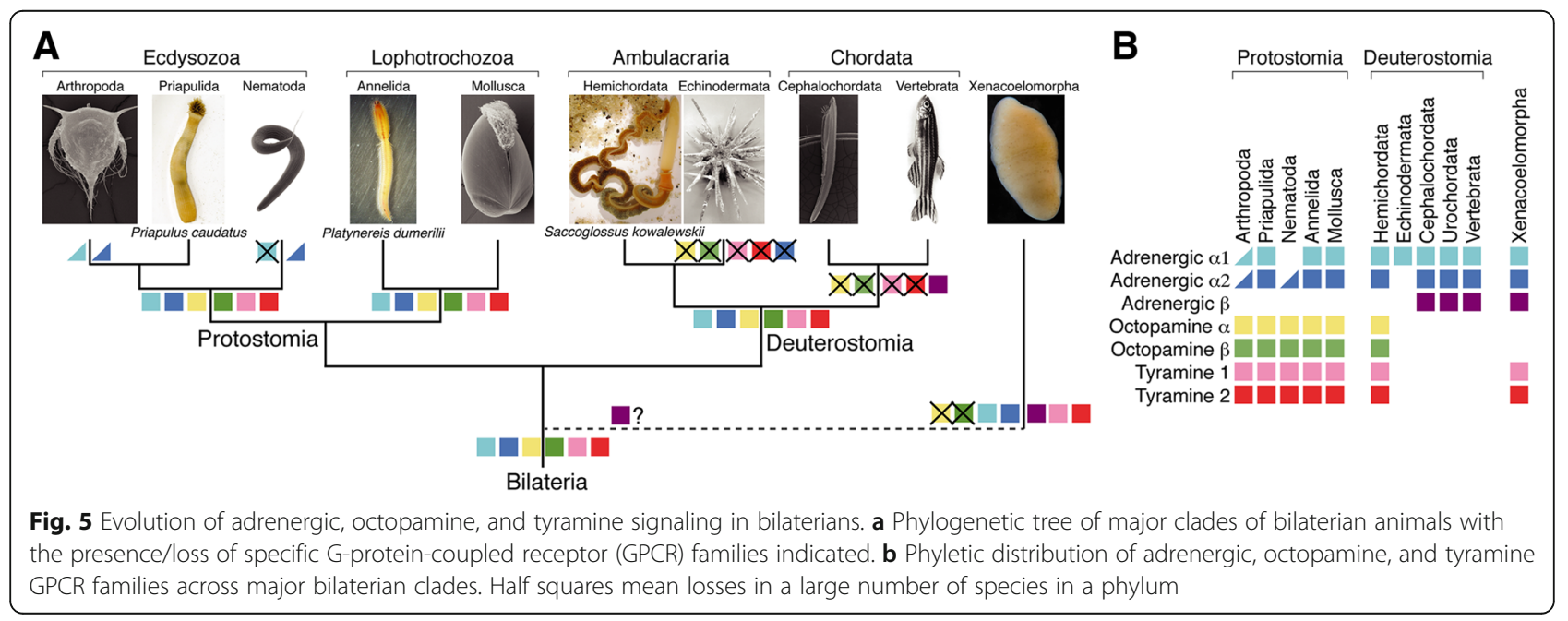


tyramine, and adrenergic receptors were present in the bilaterian last common ancestor (Additional file 11). These include the adrenergic $\alpha 1$ and $\alpha 2$ receptors, the tyramine type 1 and type 2 receptors, and the octopamine $\alpha$ and $\beta$ receptors. From the six ancestral families, the octopamine and tyramine receptors have been lost from most deuterostomes, and the adrenergic receptors from most ecdysozoans. Interestingly, the xenacoelomorph $M$. stichopi also has an adrenergic $\beta$ receptor, representing the only ortholog outside chordates. Octopamine $\alpha$ receptors have likely been lost from xenacoelomorphs, given that the split of the six receptor families (four with well-resolved xenacoelomorph sequences) pre-dated the divergence of the main lineages of bilaterians (Fig. 1c).

Although we performed the receptor activation assays in a heterologous system that might not mimic the in vivo situation very well, we found clear evidence of ligand preferences for each receptor. In general, there was two orders of magnitude difference in the $\mathrm{EC}_{50}$ values between the best ligand and other related ligands for the same receptor measured under the same conditions. We consider these in vitro ligand preferences as indicative of the physiological ligands for these receptors. Furthermore, there was high congruence between the in vitro ligand specificities and the phylogenetic placement of the different classes of receptors, further strengthening our receptor-type assignments. The most potent ligand of all six orthologous receptor families we analyzed was the same across protostomes and deuterostomes, indicating the evolutionary stability of ligandreceptor pairs, similar to the long-term stability of neuropeptide GPCR ligand-receptor pairs [34, 35].

Understanding the ancestral role of these signaling systems and why they may have been lost differentially in different animal groups will require functional studies in organisms where all three neurotransmitter systems coexist.

\section{Conclusions}

We have established the coexistence of adrenergic, octopaminergic, and tyraminergic signaling in the deuterostome S. kowalevskii and the protostomes Platynereis dumerilii and Priapulus caudatus. Signaling by norepinephrine in vertebrates has often been considered as equivalent to signaling by octopamine in invertebrates. Our results change this view and show that these signaling systems coexisted ancestrally and still coexist in some bilaterians. The extent of functional redundancy in species where all six receptor systems coexist will require experimental studies. It may be that some of these monoamines ancestrally had partially overlapping roles. In that case, following the loss of a receptor, functions associated with that ligand-receptor pair may have been taken over by another pair. However, regardless of such potential shifts in function, it is clear that octopamine signaling in invertebrates and adrenergic signaling in vertebrates is not equivalent or homologous from an evolutionary point of view. This has important implications for our interpretation of comparative studies of the function of these neurotransmitter systems and their neural circuits. Our study also contributes to the understanding of nervous system evolution in bilaterians by revealing extensive losses during the history of one of the major classes of neurotransmitter systems.

\section{Methods}

\section{Gene identification and receptor cloning}

Platynereis protein sequences were collected from a Platynereis mixed-stage transcriptome assembly [36]. GPCR sequences from other species were downloaded from NCBI. GPCRs were cloned into pcDNA3.1(+) (Thermo Fisher Scientific, Waltham, MA, USA) as described before [31]. Forward primers consisted of a spacer (ACAATA) followed by a BamHI or EcoRI restriction site, the Kozak consensus sequence (CGCCACC), a start codon (ATG), and a sequence corresponding to the target sequence. Reverse primers consisted of a spacer (ACAATA), a NotI restriction site, a STOP codon, and a reverse complementary sequence to the target sequence. Primers were designed to end with a $\mathrm{C}$ or $\mathrm{G}$ with a $72{ }^{\circ} \mathrm{C}$ melting temperature. Polymerase chain reaction was performed using Phusion polymerase (New England Biolabs GmbH, Frankfurt, Germany). The sequences of all Platynereis GPCRs tested here were deposited in GenBank (accession numbers: $\alpha 1$-adrenergic receptor [GenBank: KX372342]; $\alpha 2$-adrenergic receptor [GenBank: KX372343], Tyramine-1 receptor [GenBank: KP293998]; Tyramine-2 receptor [GenBank: KU715093]; Octopamine $\alpha$ receptor [GenBank: KU530199]; Octopamine $\beta$ receptor [GenBank: KU886229]). Tyramine receptor 1 has previously been published [31] as Pdu orphan GPCR 48. The GenBank accession numbers of the $S$. kowalevskii and Priapulus caudatus sequences tested are: S. kowalevskii a1-adrenergic [GenBank: ALR88680]; S. kowalevskii $\alpha 2$ adrenergic [GenBank: XP_002734932]; Priapulus caudatus $\alpha 1$-adrenergic [GenBank: XP_014662992]; Priapulus caudatus $\alpha 2$-adrenergic [GenBank: XP_014681069]; S. kowalevskii Tyramine-1 [GenBank: XP_002742354]; S. kowalevskii Tyramine-2A [GenBank: XP_002734062]; S. kowalevskii Tyramine-2B [GenBank: XP_006812999]; S. kowalevskii Octopamine $\alpha$, [GenBank: XP_006823182]; and S. kowalevskii Octopamine $\beta$ [GenBank: XP_ 002733926].

\section{Cell culture and receptor deorphanization}

Cell culture assays were done as described before [31]. Briefly, CHO-K1 cells were kept in Ham's F12 Nut Mix 
medium (Thermo Fisher Scientific) with 10\% fetal bovine serum and penicillin-streptomycin (PenStrep, Thermo Fisher Scientific). Cells were seeded in 96-well plates (Thermo Fisher Scientific) at approximately 10,000 cells/well. After 1 day, cells were transfected with plasmids encoding a GPCR, the promiscuous G $\alpha-16$ protein [37], and a reporter construct GFP-apoaequorin [38] (60 ng each) using $0.375 \mu \mathrm{L}$ of the transfection reagent TurboFect (Thermo Fisher Scientific). After 2 days of expression, the medium was removed and replaced with Hank's Balanced Salt Solution (HBSS) supplemented with $1.8 \mathrm{mM} \mathrm{Ca}^{2+}, 10 \mathrm{mM}$ glucose, and $1 \mathrm{mM}$ coelenterazine $\mathrm{h}$ (Promega, Madison, WI, USA). After incubation at $37^{\circ} \mathrm{C}$ for $2 \mathrm{~h}$, cells were tested by adding synthetic monoamines (Sigma, St. Louis, MO, USA) in HBSS supplemented with $1.8 \mathrm{mM} \mathrm{Ca}^{2+}$ and $10 \mathrm{mM}$ glucose. Solutions containing norepinephrine, epinephrine, or dopamine were supplemented with $100 \mu \mathrm{M}$ ascorbic acid to prevent oxidation. Luminescence was recorded for $45 \mathrm{~s}$ in a plate reader (BioTek Synergy Mx or Synergy H4; BioTek, Winooski, VT, USA). For inhibitor testing, the cells were incubated with yohimbine or mianserin (Sigma) for $1 \mathrm{~h}$. Then, synthetic monoamines were added to yield in each case the smallest final concentration expected to elicit the maximal response in the absence of inhibitor, and luminescence was recorded for $45 \mathrm{~s}$. Data were integrated over the 45 -s measurement period. Data for dose-response curves were recorded as technical triplicates for each concentration. Measurements were performed from adjacent wells on the same plate to minimize variation introduced by cell seeding and transfection. Dose-response curves were fitted with a four-parameter curve using Prism 6 (GraphPad, La Jolla, CA, USA). The curves were normalized to the calculated upper plateau values $(100 \%$ activation). The different $\mathrm{EC}_{50}$ values for each receptor were compared with the extra sum-of-squares $F$ test in a pairwise manner using Prism 6.

\section{Bioinformatics}

Protein sequences were downloaded from the NCBI. Redundant sequences were removed from the collection using CD-HIT [39] with an identity cutoff of $70 \%$. Sequence cluster maps were created with CLANS2 [40] using the BLOSUM62 matrix and a $P$-value cutoff of 1e-70. For phylogenetic trees, protein sequences were aligned with MUSCLE [41]. Alignments were trimmed with TrimAI [42] in "Automated 1" mode. The best amino acid substitution model was selected using ProtTest 3 [43]. Maximum likelihood trees were calculated with RAxML [44] using the CIPRES Science Gateway [45] or with IQ-TREE and automatic model selection (http://www.iqtree.org/). Bootstrap analysis in RAxML was done and automatically stopped [46] when the Majority Rule Criterion (autoMRE) was met. The resulting trees were visualized with FigTree (http://tree.bio.ed.ac.uk/software/figtree/). The identifiers of deorphanized adrenergic, octopamine, and tyramine receptors [12, 29, 47-59] were tagged with _AA1, AA2,_Oa,_Ob, _T1, or _T2. The trees were rooted on $5 \mathrm{HT}$ receptors. The full phylogenetic tree is available in nexus format (Additional file 11).

\section{Additional files}

Additional file 1: Maximum likelihood tree of adrenergic, octopamine and tyramine receptors. Bootstrap support values are shown. This tree contains all investigated GPCRs. The tree was rooted on $5 \mathrm{HT}$ receptor sequences. Sub-trees are shown in Additional files 2, 3, 4, 5, 6, 7, and 8. (PDF $118 \mathrm{~kb}$ )

Additional file 2: Maximum likelihood tree of a1-adrenergic receptors Bootstrap support values are shown for selected nodes. This tree is part of a larger tree containing all investigated GPCRs. (PDF 16992 kb)

Additional file 3: Maximum likelihood tree of a2-adrenergic receptors. Bootstrap support values are shown for selected nodes. This tree is part of a larger tree containing all investigated GPCRs. (PDF $17168 \mathrm{~kb}$ )

Additional file 4: Maximum likelihood tree of $\beta$-adrenergic receptors. Bootstrap support values are shown for some nodes of interest. This tree is part of a larger tree containing all investigated GPCRs. (PDF $759 \mathrm{~kb}$ )

Additional file 5: Maximum likelihood tree of tyramine type 1 receptors. Bootstrap support values are shown for selected nodes. This tree is part of a larger tree containing all investigated GPCRs. The identifiers of deorphanized tyramine receptors were tagged with _T1. (PDF 17028 kb)

Additional file 6: Maximum likelihood tree of tyramine type 2 receptors. Bootstrap support values are shown for selected nodes. This tree is part of a larger tree containing all investigated GPCRs. The identifiers of deorphanized tyramine receptors were tagged with _ T2. (PDF 17007 kb)

Additional file 7: Maximum likelihood tree of octopamine-a receptors. Bootstrap support values are shown for selected nodes. This tree is part of a larger tree containing all investigated GPCRs. The identifiers of deorphanized octopamine receptors were tagged with _Oa. (PDF 16730 kb)

Additional file 8: Maximum likelihood tree of octopamine- $\beta$ receptors. Bootstrap support values are shown for selected nodes. This tree is part of a larger tree containing all investigated GPCRs. The identifiers of deorphanized octopamine receptors were tagged with _Ob. (PDF $16730 \mathrm{~kb}$ )

Additional file 9: Maximum likelihood tree of tyrosine decarboxylase and aromatic amino acid decarboxylase enzymes. Bootstrap support values are shown for selected nodes. P. dumerilii, P. caudatus, and S. kowalevskii sequences are highlighted in color. The Caenorhabditis elegans tyrosine decarboxylase was experimentally shown to be required for tyramine biosynthesis [32]. (PDF $566 \mathrm{~kb}$ )

Additional file 10: Dose-response curves of adrenergic, tyramine, and octopamine receptors from P. dumerilii, P. caudatus, and S. kowalevskii treated with varying concentrations of inhibitors. Data, representing luminescence units relative to the maximum of the fitted dose-response curves, are shown as mean $\pm \operatorname{SEM}(n=3)$. $I C_{50}$ values are listed in Table 1. (TIF $956 \mathrm{~kb}$ )

Additional file 11: Maximum likelihood tree of octopamine, tyramine, and adrenergic a receptors, in nexus format. (NEXUS $37 \mathrm{~kb}$ )

\section{Acknowledgments}

We thank John Gerhart for Saccoglossus DNA and the image of Saccoglossus. We thank Mattias Hogvall for Priapulus DNA and the image of Priapulus, and Anne-C. Zakrzewski for the Xenoturbella image. We also thank Elizabeth Williams for comments on the manuscript. 


\section{Funding}

The research leading to these results received funding from the European Research Council under the European Union's Seventh Framework Programme (FP7/2007-2013)/ European Research Council Grant Agreement 260821. PB is supported by the International Max Planck Research School (IMPRS) "From Molecules to Organisms."

The funding bodies had no role in the design of the study; collection, analysis, and interpretation of data; or in writing the manuscript.

\section{Availability of data and materials}

GenBank accession numbers are listed in the Methods. All data generated or analyzed during this study are included in this published article and its supplementary information files. All data on which our conclusions depend are available on reasonable request.

\section{Authors' contributions}

PG and GJ performed phylogenetic analysis. PG performed gene cloning and receptor pharmacology. PB and GJ designed the study and wrote the paper. Both authors read and approved the final manuscript.

\section{Competing interests}

The authors declare that they have no competing interests.

\section{Consent for publication}

Not applicable.

\section{Ethics approval and consent to participate}

Not applicable.

Received: 12 October 2016 Accepted: 6 December 2016 Published online: 30 January 2017

\section{References}

1. Singh C, Oikonomou G, Prober DA. Norepinephrine is required to promote wakefulness and for hypocretin-induced arousal in zebrafish. elife. 2015;4, e07000

2. Marino MD, Bourdélat-Parks BN, Cameron Liles L, Weinshenker D. Genetic reduction of noradrenergic function alters social memory and reduces aggression in mice. Behav Brain Res. 2005;161:197-203.

3. Kim CH, Zabetian CP, Cubells JF, Cho S, Biaggioni I, Cohen BM, Robertson D, Kim KS. Mutations in the dopamine beta-hydroxylase gene are associated with human norepinephrine deficiency. Am J Med Genet. 2002;108:140-7.

4. Roeder T. Tyramine and octopamine: ruling behavior and metabolism. Annu Rev Entomol. 2005:50:447-77.

5. Zhou C, Rao Y, Rao Y. A subset of octopaminergic neurons are important for Drosophila aggression. Nat Neurosci. 2008:11:1059-67.

6. Crocker A, Sehgal A. Octopamine regulates sleep in drosophila through protein kinase A-dependent mechanisms. J Neurosci. 2008;28:9377-85.

7. Crisp KM, Grupe RE, Lobsang TT, Yang X. Biogenic amines modulate pulse rate in the dorsal blood vessel of Lumbriculus variegatus. Comp Biochem Physiol C Toxicol Pharmacol. 2010;151:467-72.

8. Florey E, Rathmayer M. The effects of octopamine and other amines on the heart and on neuromuscular transmission in decapod crustaceans: further evidence for a role as neurohormone. Comp Biochem Physiol Part C. 1978; 61:229-37

9. Jin X, Pokala N, Bargmann Cl. Distinct circuits for the formation and retrieval of an imprinted olfactory memory. Cell. 2016;164:632-43.

10. Nagaya Y, Kutsukake M, Chigusa SI, Komatsu A. A trace amine, tyramine, functions as a neuromodulator in Drosophila melanogaster. Neurosci Lett. 2002:329:324-8

11. Saudou F, Amlaiky N, Plassat JL, Borrelli E, Hen R. Cloning and characterization of a Drosophila tyramine receptor. EMBO J. 1990:9:3611-7.

12. Rex E, Komuniecki RW. Characterization of a tyramine receptor from Caenorhabditis elegans. J Neurochem. 2002:82:1352-9.

13. Kutsukake M, Komatsu A, Yamamoto D, Ishiwa-Chigusa S. A tyramine receptor gene mutation causes a defective olfactory behavior in Drosophila melanogaster. Gene. 2000;245:31-42.

14. Selcho M, Pauls D, El Jundi B, Stocker RF, Thum AS. The role of octopamine and tyramine in Drosophila larval locomotion. J Comp Neurol. 2012:520:3764-85.
15. Huang J, Liu W, Qi YX, Luo J, Montell C. Neuromodulation of courtship drive through tyramine-responsive neurons in the Drosophila brain. Curr Biol. 2016;26:2246-56.

16. Wallace BG. The biosynthesis of octopamine-characterization of lobster tyramine beta-hydroxylase. J Neurochem. 1976;26:761-70.

17. Monastirioti M, Linn CE, White K. Characterization of Drosophila tyramine beta-hydroxylase gene and isolation of mutant flies lacking octopamine. J Neurosci. 1996;16:3900-11.

18. Evans PD, Maqueira B. Insect octopamine receptors: a new classification scheme based on studies of cloned Drosophila G-protein coupled receptors. Invert Neurosci. 2005:5:111-8.

19. Cazzamali G, Klaerke DA, Grimmelikhuijzen CJ. A new family of insect tyramine receptors. Biochem Biophys Res Commun. 2005:338:1189-96.

20. Borowsky B, Adham N, Jones KA, Raddatz R, Artymyshyn R, Ogozalek KL, Durkin MM, Lakhlani PP, Bonini JA, Pathirana S, Boyle N, Pu X, Kouranova E, Lichtblau H, Ochoa FY, Branchek TA, Gerald C. Trace amines: identification of a family of mammalian G protein-coupled receptors. Proc Natl Acad Sci U S A. 2001;98:8966-71.

21. Eyun SI, Moriyama H, Hoffmann FG, Moriyama EN. Molecular evolution and functional divergence of trace amine-associated receptors. PLoS One. 2016; 11, e0151023.

22. Gallo VP, Accordi F, Chimenti C, Civinini A, Crivellato E. Catecholaminergic system of invertebrates: comparative and evolutionary aspects in comparison with the octopaminergic system. Int Rev Cell Mol Biol. 2016; 322:363-94.

23. Arakawa S, Gocayne JD, McCombie WR, Urquhart DA, Hall LM, Fraser CM, Venter JC. Cloning, localization, and permanent expression of a Drosophila octopamine receptor. Neuron. 1990:4:343-54.

24. Dunn C, Giribet G, Edgecombe G, Hejnol A. Animal phylogeny and its evolutionary implications. Annu Rev Ecol Evol Syst. 2014:45:371-95.

25. Bourlat SJ, Juliusdottir T, Lowe CJ, Freeman R, Aronowicz J, Kirschner M, Lander ES, Thorndyke M, Nakano H, Kohn AB, Heyland A, Moroz LL, Copley $\mathrm{RR}$, Telford MJ. Deuterostome phylogeny reveals monophyletic chordates and the new phylum Xenoturbellida. Nature. 2006:444:85-8.

26. Cannon JT, Vellutini BC, Smith J, Ronquist F, Jondelius U, Hejnol A. Xenacoelomorpha is the sister group to Nephrozoa. Nature. 2016;530:89-93.

27. Philippe H, Brinkmann H, Copley RR, Moroz LL, Nakano H, Poustka AJ, Wallberg A, Peterson KJ, Telford MJ. Acoelomorph flatworms are deuterostomes related to Xenoturbella. Nature. 2011;470:255-8.

28. Krishnan A, Almén MS, Fredriksson R, Schiöth HB. Remarkable similarities between the hemichordate (Saccoglossus kowalevskii) and vertebrate GPCR repertoire. Gene. 2013;526:122-33.

29. Wu SF, Xu G, Qi YX, Xia RY, Huang J, Ye GY. Two splicing variants of a nove family of octopamine receptors with different signaling properties. $J$ Neurochem. 2014:129:37-47.

30. Tunaru S, Lättig J, Kero J, Krause G, Offermanns S. Characterization of determinants of ligand binding to the nicotinic acid receptor GPR109A (HM74A/PUMA-G). Mol Pharmacol. 2005;68:1271-80.

31. Bauknecht $P$, Jékely $G$. Large-scale combinatorial deorphanization of Platynereis neuropeptide GPCRs. Cell Rep. 2015;12:684-93.

32. Alkema MJ, Hunter-Ensor M, Ringstad N, Horvitz HR. Tyramine functions independently of octopamine in the Caenorhabditis elegans nervous system. Neuron. 2005:46:247-60.

33. Lovenberg W, Weissbach $H$, Udenfriend S. Aromatic L-amino acid decarboxylase. J Biol Chem. 1962;237:89-93.

34. Jékely G. Global view of the evolution and diversity of metazoan neuropeptide signaling. Proc Natl Acad Sci U S A. 2013;110:8702-7.

35. Mirabeau O, Joly JS. Molecular evolution of peptidergic signaling systems in bilaterians. Proc Natl Acad Sci U S A. 2013;110:E2028-37.

36. Conzelmann M, Williams EA, Krug K, Franz-Wachtel M, Macek B, Jékely G. The neuropeptide complement of the marine annelid Platynereis dumerilii. BMC Genomics. 2013;14:906.

37. Offermanns S, Simon MI. G alpha 15 and $\mathrm{G}$ alpha 16 couple a wide variety of receptors to phospholipase C. J Biol Chem. 1995:270:15175-80.

38. Baubet V, Le Mouellic H, Campbell AK, Lucas-Meunier E, Fossier P, Brúlet P. Chimeric green fluorescent protein-aequorin as bioluminescent $\mathrm{Ca} 2+$ reporters at the single-cell level. Proc Natl Acad Sci U S A. 2000;97:7260-5.

39. Li W, Godzik A. Cd-hit: a fast program for clustering and comparing large sets of protein or nucleotide sequences. Bioinformatics. 2006;22:1658-9.

40. Frickey T, Lupas A. CLANS: a Java application for visualizing protein families based on pairwise similarity. Bioinformatics. 2004;20:3702-4. 
41. Edgar RC. MUSCLE: a multiple sequence alignment method with reduced time and space complexity. BMC Bioinformatics. 2004;5:113.

42. Capella-Gutiérrez S, Silla-Martínez JM, Gabaldón T. trimAl: a tool for automated alignment trimming in large-scale phylogenetic analyses. Bioinformatics. 2009;25:1972-3.

43. Darriba D, Taboada GL, Doallo R, Posada D. ProtTest 3: fast selection of best-fit models of protein evolution. Bioinformatics. 2011;27:1164-5.

44. Stamatakis A. RAxML version 8: a tool for phylogenetic analysis and postanalysis of large phylogenies. Bioinformatics. 2014;30:1312-3.

45. Miller MA, Pfeiffer W, Schwartz T. Creating the CIPRES Science Gateway for inference of large phylogenetic trees. In: 2010 Gateway Computing Environments Workshop (GCE). New Orleans: IEEE; 2010:1-8

46. Pattengale ND, Alipour M, Bininda-Emonds OR, Moret BM, Stamatakis A. How many bootstrap replicates are necessary? J Comput Biol. 2010;17:337-54.

47. Balfanz S, Jordan N, Langenstück T, Breuer J, Bergmeier V, Baumann A. Molecular, pharmacological, and signaling properties of octopamine receptors from honeybee (Apis mellifera) brain. J Neurochem. 2014;129:284-96.

48. Verlinden H, Vleugels R, Marchal E, Badisco L, Pflüger HJ, Blenau W, Broeck JV. The role of octopamine in locusts and other arthropods. J Insect Physiol. 2010;56:854-67.

49. Gross AD, Temeyer KB, Day TA, de Pérez León AA, Kimber MJ, Coats JR. Pharmacological characterization of a tyramine receptor from the southern cattle tick, Rhipicephalus (Boophilus) microplus. Insect Biochem Mol Biol. 2015;63:47-53.

50. Kastner KW, Shoue DA, Estiu GL, Wolford J, Fuerst MF, Markley LD, Izaguirre JA, McDowell MA. Characterization of the Anopheles gambiae octopamine receptor and discovery of potential agonists and antagonists using a combined computational-experimental approach. Malar J. 2014;13:434

51. Wu SF, Yao Y, Huang J, Ye GY. Characterization of a $\beta$-adrenergic-like octopamine receptor from the rice stem borer (Chilo suppressalis). J Exp Biol. 2012;215(Pt 15):2646-52.

52. Huang J, Wu SF, Li XH, Adamo SA, Ye GY. The characterization of a concentration-sensitive a-adrenergic-like octopamine receptor found on insect immune cells and its possible role in mediating stress hormone effects on immune function. Brain Behav Immun. 2012;26:942-50.

53. Lind U, Alm Rosenblad M, Hasselberg Frank L, Falkbring S, Brive L, Laurila JM, Pohjanoksa K, Vuorenpää A, Kukkonen JP, Gunnarsson L, Scheinin M, Mårtensson Lindblad LG, Blomberg A. Octopamine receptors from the barnacle Balanus improvisus are activated by the alpha2-adrenoceptor agonist medetomidine. Mol Pharmacol. 2010;78:237-48.

54. Chen X, Ohta H, Ozoe F, Miyazawa K, Huang J, Ozoe Y. Functional and pharmacological characterization of a beta-adrenergic-like octopamine receptor from the silkworm Bombyx mori. Insect Biochem Mol Biol. 2010;40: 476-86.

55. Blais V, Bounif N, Dubé F. Characterization of a novel octopamine receptor expressed in the surf clam Spisula solidissima. Gen Comp Endocrinol. 2010; 167:215-27.

56. Chang DJ, Li XC, Lee YS, Kim HK, Kim US, Cho NJ, Lo X, Weiss KR, Kandel ER, Kaang BK. Activation of a heterologously expressed octopamine receptor coupled only to adenylyl cyclase produces all the features of presynaptic facilitation in aplysia sensory neurons. Proc Natl Acad Sci U S A. 2000;97: 1829-34.

57. Gerhardt CC, Bakker RA, Piek GJ, Planta RJ, Vreugdenhil E, Leysen JE, Van Heerikhuizen $\mathrm{H}$. Molecular cloning and pharmacological characterization of a molluscan octopamine receptor. Mol Pharmacol. 1997;51:293-300.

58. Wu SF, Xu G, Ye GY. Characterization of a tyramine receptor type 2 from hemocytes of rice stem borer, Chilo suppressalis. J Insect Physiol. 2015;75:39-46.

59. Jezzini SH, Reyes-Colón D, Sosa MA. Characterization of a prawn OA/TA receptor in Xenopus oocytes suggests functional selectivity between octopamine and tyramine. PLoS One. 2014;9, e111314.

\section{Submit your next manuscript to BioMed Central and we will help you at every step:}

- We accept pre-submission inquiries

- Our selector tool helps you to find the most relevant journal

- We provide round the clock customer support

- Convenient online submission

- Thorough peer review

- Inclusion in PubMed and all major indexing services

- Maximum visibility for your research

Submit your manuscript at www.biomedcentral.com/submit
Biomed Central 